\title{
Does transcutaneous electrical nerve stimulation reduce pain and improve quality of life in patients with idiopathic chronic orchialgia? A randomized controlled trial
}

This article was published in the following Dove Press journal:

Journal of Pain Research

\author{
Sayed A Tantawy ${ }^{1,2}$ \\ Dalia $\mathrm{M} \mathrm{Kamel}^{3}$ \\ Walid Kamal Abdelbasset ${ }^{4,5}$ \\ 'Department of Physiotherapy, Centre \\ of Radiation, Oncology and Nuclear \\ Medicine, Cairo University, Giza, \\ Egypt; ${ }^{2}$ Department of Physiotherapy, \\ College of Medical and Health \\ Sciences, Ahlia University, Manama, \\ Kingdom of Bahrain; ${ }^{3}$ Department \\ of Physical Therapy for Obstetrics \\ \& Gynecology, Faculty of Physical \\ Therapy, Cairo University, Giza, Egypt; \\ ${ }^{4}$ Department of Physical Therapy \\ and Health Rehabilitation, College \\ of Applied Medical Sciences, Prince \\ Sattam Bin Abdul Aziz University, \\ Alkharj, Saudi Arabia; ${ }^{5}$ Department \\ of Physical Therapy, Kasr Al-Aini \\ Hospital, Cairo University, Giza, Egypt
}

Correspondence: Sayed A Tantawy PO Box 10878, Manama, Kingdom of Bahrain

Tel +97336883977

Fax +973 17290083

Email tantawyss@yahoo.com
Background: Chronic orchialgia is defined as testicular pain, which may be either unilateral or bilateral, lasting for more than 3 months. It disturbs a patient's daily activities and quality of life (QoL), inciting the patient to search for treatments to alleviate the pain. It is estimated that $25 \%$ of chronic orchialgia cases are idiopathic.

Purpose: The purpose of this study was to investigate how effective transcutaneous electrical nerve stimulation (TENS) is in pain reduction and how it consequently affects the QoL in patients with idiopathic chronic orchialgia (ICO).

Patients and methods: Seventy-one patients were randomly assigned to group A (study group), which included 36 patients who received TENS and analgesia, and group B (control group), which included 35 patients who received analgesia only. The outcome measures were the participants' demographic data and results of the visual analog scale (VAS) and QoL questionnaire. These outcomes were measured before and after 4 weeks of treatment and at 2-month follow-up.

Results: The results showed that compared to pretreatment, there was a significant reduction in pain postintervention and at 2-month follow-up in group A $(P<0.0001$ and $<0.001$, respectively; $F=7.1)$ as well as a significant improvement in QoL at these time points $(P<0.0001$ and $<0.0001$, respectively). There were no significant differences in the VAS score and QoL in group B at different time points of evaluation.

Conclusion: The findings indicate that TENS is effective in reducing pain and improving patients' QoL in cases of ICO. TENS is an easy-to-use, effective, noninvasive, and simple method for ICO-associated pain control and QoL improvement.

Keywords: orchialgia, testicular pain, TENS, pain assessment, VAS, physiotherapy, quality of life, chronic pain

\section{Introduction}

Idiopathic chronic orchialgia (ICO) is a stressful clinical condition for both the patient and the doctor. It may develop at any age, but the majority of patients are young males, 20-30 years old, with persistent or intermittent unilateral or bilateral scrotal pain lasting at least 3 months. This pain significantly disturbs the patient's daily activities and quality of life (QoL), inciting the patient to search for suitable treatment. ${ }^{1-3}$

Chronic orchialgia may be caused by tumors, inguinal hernias, infections, varicoceles, hydroceles, spermatoceles, trauma, radiating pain, or postoperative vasectomy or herniography. ${ }^{4,5}$ It has been estimated to be idiopathic in $25-50 \%$ of patients. In these 
cases with unknown etiology, the pain may be recalcitrant to several types of treatment. ${ }^{6,7}$

Conservative treatment includes scrotal support, antibiotics and analgesics, ${ }^{7}$ alpha-adrenergic antagonists, tricyclic antidepressants, gabapentin and carbamazepine, and allopurinol. ${ }^{8,9}$ Possible surgical treatment for ICO includes microsurgical denervation of the spermatic cord, ${ }^{10}$ microsurgical testicular denervation, ${ }^{11}$ and orchiectomy. ${ }^{1,5,7}$ There are many physical therapy modalities to relieve and control ICO-associated pain, such as transcutaneous electrical nerve stimulation (TENS), interferential (IF) therapy, pelvic floor muscle training, and radiofrequency treatment. ${ }^{12-15}$

TENS is a nonpharmacological and noninvasive method generally utilized for the treatment of acute and chronic pain. Despite various clinical trials demonstrating the effectivity of TENS for pain reduction, there is still much debate over which conditions TENS should be used to treat and what parameters must be utilized for these treatments. Earlier reports demonstrated that TENS diminishes pain through both central and peripheral mechanisms. Centrally, opioid, serotonin, and muscarinic receptors in the spinal cord and brainstem are stimulated by TENS. Peripherally, opioid and $\alpha-2$ noradrenergic receptors are involved in TENS-induced analgesia. ${ }^{16}$

TENS is one of the most widely used electroanalgesia modalities. It is used for different types of conditions, such as rheumatoid and arthritic, neuropathic, lower back, and cancer-related pain. ${ }^{17-20}$

ICO is a chronic condition and requires conservative treatment. Furthermore, it is clear that TENS is widely used in different cases. To our knowledge, there are limited data about its application in treating ICO; thus, the aim of this study was to investigate the effect of TENS on patients with ICO.

\section{Patients and methods}

The initial sample was male patients suffering from ICO; they were invited and examined for eligibility to participate in the study as shown in Figure 1. The study design was a doubleblind, randomized controlled trial. The study procedures were approved by the Faculty of Physical Therapy, Cairo University's local ethical committee, according to the Declaration of Helsinki principles, and written informed consent forms were completed before initiating the study. Seventy-one male patients aged between 21 and 30 years were recruited from the Department of Urology, Kasr El Eini Hospital, Cairo University. These patients had been suffering from unilateral ICO for $>6$ months and had not benefited from previously administered medications. Patients with defined causes of orchialgia with pathological inflammation such as epididymal cysts, hydroceles, testicular tumors, and spermatoceles were excluded from the trial. Laboratory investigations and scrotum sonography were performed to identify and exclude cases of orchialgia having paratesticular causes.

The patients were randomly assigned to group A (study group), which included 36 patients who received TENS and analgesia, and group B (control group), which included 35 patients who received analgesia only. TENS application (ENS 931; Enraf Nonius, the Netherlands) was performed five times per week for 4 weeks (TENS frequency, $100 \mathrm{~Hz}$; pulse width, $100 \mu \mathrm{s}$; duration, 30 minutes). Self-adhesive electrodes, size $50 \mathrm{~mm} \times 50 \mathrm{~mm}$, were used, and the anode electrode was placed on the lower abdomen (suprapubic area medial to the iliofemoral ligament) in the area with the highest pain and the cathode electrode placed $5 \mathrm{~cm}$ proximal to the anode in relation to the trunk side. TENS intensity was set according to the patient's tolerance with a mean of $25 \mathrm{~mA}$.

Sensation tests were conducted on the skin at the site of pain by utilizing two test tubes containing cool and warm water; similarly, a light touch was achieved by means of a pin prick. Sensation was determined to be intact, and there was no resistance for the stimulation to be effective.

The outcome measures were the participants' demographic data and scores of visual analog scale (VAS) and QoL. These outcomes were measured before and after 4 weeks of treatment and at 2-month follow-up.

The VAS is reliable, valid, and sensitive to change in pharmacological and nonpharmacological trials. It is a self-evaluated scale along a $10 \mathrm{~cm}$ (ie, $100 \mathrm{~mm}$ ) line; the participant places a perpendicular line on the scale at the point that reflects his pain intensity. A higher score indicates greater pain intensity. The following cutoff points on the pain VAS have been recommended: no pain $(0-4 \mathrm{~mm})$, mild pain (5-44 mm), moderate pain (45-74 $\mathrm{mm})$, and severe pain ( $75-100 \mathrm{~mm})$. Pain is a subjective sensation; thus, normative values are not available. ${ }^{21}$

QoL was evaluated using the following question on the test that was administered beforehand: "If you were to spend the rest of your life with your symptoms just the way they have been during the last month, how would you feel about that?" Scores for this question were measured on a scale from 1 to 7 , as $1=$ delighted, $2=$ pleased, $3=$ mostly satisfied, $4=$ mixed, $5=$ mostly dissatisfied, $6=$ unhappy, and $7=$ terrible. ${ }^{22}$

\section{Statistical analysis}

All the collected data were tabulated in the PASW Statistics Version 18 to apply both descriptive and inferential statistics. The paired $t$-test was used to indicate intergroup differences. 


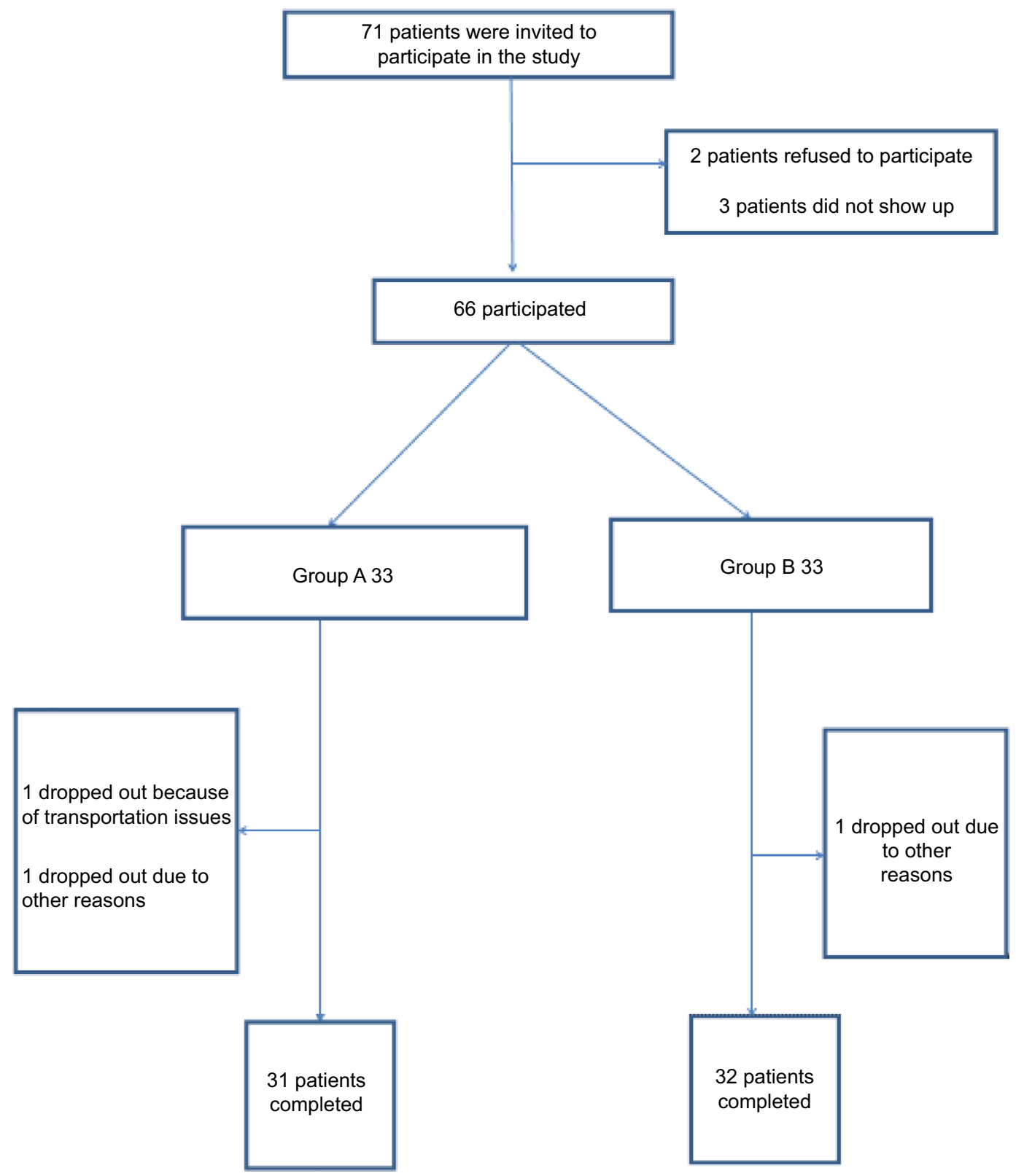

Figure I Study flowchart.

Analysis of variance (ANOVA) was used to compare the effect of TENS in both groups pre- and postintervention and at follow-up. The chi-square test was used to compare the QoL in both groups. The $P$-value was set at 5\%.

\section{Results}

There was no significant difference between groups $\mathrm{A}$ and $\mathrm{B}$ in terms of demographics $(P>0.05)$, as presented in Table 1 .

Results showed that in group A, there were significant differences between the VAS score pre- and postintervention and at 2-month follow-up $(P<0.0001$ and $<0.001$, respectively; $F=7.1$ ). In group $\mathrm{B}$, there were no significant differences in VAS scores at different time points of measurements.
Table I Demographic data for group A and group B

\begin{tabular}{llll}
\hline Category & Group A & Group B & P-value \\
\hline Age (years) & $26.55 \pm 2.64$ & $26.30 \pm 2.5 \mathrm{I}$ & 0.76 \\
Weight $(\mathrm{kg})$ & $76.85 \pm 5.23$ & $76.3 \pm 5.99$ & 0.75 \\
Height $(\mathrm{m})$ & $1.75 \pm 0.082$ & $1.76 \pm 0.079$ & 0.81 \\
BMI $\left(\mathrm{kg} / \mathrm{m}^{2}\right)$ & $24.94 \pm 2.19$ & $24.58 \pm 2.27$ & 0.61 \\
Duration of pain (months) & $\mathrm{Il} .65 \pm 2.34$ & $1 \mathrm{l} .05 \pm \mathrm{I} .63$ & 0.35 \\
\hline
\end{tabular}

Notes: Data are presented as mean \pm standard deviation. Group A, study group; Group B, control group.

Abbreviation: BMI, body mass index.

Intergroup comparisons showed significant differences at the end of intervention and at 2-month follow-up in favor of group A, as shown in Table 2. 
In group A, there was a significant improvement in patient QoL. The QoL was significantly better postintervention than preintervention $(P<0.0001)$, and at 2-month follow-up, QoL was significantly better than it was preintervention $(P<0.0001)$. No such improvement was observed postintervention and at 2-month follow-up in group B $(P>0.05$ and $>0.05$, respectively), as shown in Table 3 . Intergroup comparisons showed significant differences at the end of intervention and at 2-month follow-up in favor of group A $(P<0.0001$ and $<0.0001$, respectively).

\section{Discussion}

Chronic pain is a common complaint and can be defined as pain experienced for more than 3 months. Smith and Torrance (2008) demonstrated that more than $50 \%$ of the adult population experiences chronic pain with genuine negative ramifications for their social and working activities, which impacts personal satisfaction levels..$^{23-25}$

The aim of the current study was to investigate the therapeutic efficacy of TENS in reducing pain associated with ICO. The results showed that there were significant differences between the VAS pre- and postintervention and at 2-month follow-up in group A $(P<0.0001$ and $<0.001$, respectively). There were no significant differences in the control group at different time points of measurements $(P>1.000)$. The results of this study revealed that TENS can significantly reduce pain in patients with ICO. This is in agreement with many studies that concluded that TENS is a noninvasive, safe, and effective mean of pain treatment. ${ }^{17-20,26}$

Table 2 VAS scores of both groups preintervention, postintervention, and after 2-month follow-up

\begin{tabular}{llllll}
\hline Category & Pre & Post I & Post 2 & P-value & F-value \\
\hline Group A & $7.35 \pm 1.13$ & $3.35 \pm 1.22$ & $4.45 \pm 0.88$ & 0.0001 & 7.1 \\
Group B & $7.30 \pm 1.26$ & $7.25 \pm 1.01$ & $6.75 \pm 1.16$ & 1.000 & 1.3 \\
P-value & 0.89 & 0.0001 & 0.0001 & & \\
\hline
\end{tabular}

Notes: Data are presented as mean \pm standard deviation. Pre, before intervention; post I, at the end of intervention; post 2, after 2-month follow-up. Group A, study group; Group B, control group.

Abbreviation: VAS, visual analog scale.
The utilization of electricity in medicine is 4000 years old. Ancient Egyptians (1200 BC) and Romans (46 AD) have utilized fish to administer electric current treatment for different illnesses. ${ }^{27,28}$ Regarding the electrotherapeutical application for ICO management, there were limited trials on the use of IF therapy showing that it is an effective physiotherapy technique and should be advised for treating ICO. ${ }^{13}$ Furthermore, there were limited trials on TENS application in ICO showing a significant effect in reducing the ICO pain. ${ }^{8,29}$ Also, a similar pain reduction effect of TENS was noted for chronic prostatitis and chronic pelvic pain. ${ }^{12,30}$

The significant reduction of pain that was observed in the TENS intervention group can be attributed to the greater activation of extrasegmental descending pain inhibitory pathways by TENS, which diffuses noxious inhibitory controls via counterirritant effects. Furthermore, antidromic activation of peripheral nerves by TENS causes blockage and extinguishes afferent impulses that have arisen from a peripheral structure (ie, "busy-line effect"). ${ }^{31,32}$ TENSinduced activity in small-diameter afferents (A-delta) leads to activation of the midbrain periaqueductal gray and rostral ventromedial medulla and inhibition of descending pain facilitatory pathways. In addition, TENS effects are mediated by many neurochemicals, including opioids, serotonin, acetylcholine, noradrenaline, and gamma-aminobutyric acid. $^{31}$

TENS used in the current study was high in frequency $(100 \mathrm{~Hz})$ and low in intensity, according to each patient's tolerance. This TENS stimulation across a range of frequencies may help to prevent the development of tolerance to electrical stimulation. ${ }^{33}$ Furthermore, high-frequency TENS has traditionally been used at lower intensities. ${ }^{33}$ We used $100 \mathrm{~Hz}$, which is supported by de Tommaso et al, ${ }^{34}$ who concluded that $100 \mathrm{~Hz}$ was effective and decreased pain ratings significantly. Also, Chakour et $\mathrm{al}^{35}$ stated that TENS with high frequency $(80 \mathrm{~Hz})$ was more effective in reducing pain than $\mathrm{CO}_{2}$ laser stimulus. Another study reported that $4 \mathrm{~Hz}$ was more effective for pain reduction, which contradicts our results. ${ }^{36}$

Table 3 The quality of life of group A and group B at different times of measurements

\begin{tabular}{|c|c|c|c|c|c|c|}
\hline \multirow[t]{2}{*}{ Category } & \multicolumn{3}{|c|}{ Group A } & \multicolumn{3}{|c|}{ Group B } \\
\hline & Pre & Post I & Post 2 & Pre & Post I & Post 2 \\
\hline Delighted & 0 & $10(50 \%)$ & $8(40 \%)$ & 0 & 0 & 0 \\
\hline Pleased & 0 & $5(25 \%)$ & $4(20 \%)$ & 0 & 0 & 0 \\
\hline Mostly satisfied & 0 & $4(20 \%)$ & $5(25 \%)$ & 0 & I (5\%) & 0 \\
\hline Mixed & I (5\%) & I (5\%) & $3(15 \%)$ & $2(10 \%)$ & $3(15 \%)$ & I (33.3\%) \\
\hline Mostly dissatisfied & $4(20 \%)$ & 0 & 0 & $5(25 \%)$ & $6(30 \%)$ & $6(62.7 \%)$ \\
\hline Unhappy & $7(35 \%)$ & 0 & 0 & $5(25 \%)$ & $5(25 \%)$ & 8 (47.47\%) \\
\hline Terrible & $8(40 \%)$ & 0 & 0 & $8(40 \%)$ & $5(25 \%)$ & $5(29.4 \%)$ \\
\hline
\end{tabular}

Notes: Pre, before intervention; post I, at the end of intervention; post 2, after 2-month follow-up. Group A, study group; Group B, control group. 
The placement of electrodes is somewhat ambiguous for local, related spinal segments. ${ }^{37}$ In the present study, the electrodes were placed on the area with the highest pain, using methods described in various studies that concluded that the maximal effects of TENS are produced when the electrodes are placed at the site of pain to deliver a strong but comfortable stimulation. ${ }^{31,32,38}$ In addition, skin impedance that may control the electrode locations is not a factor in the effectiveness of TENS when applied at comfortable intensities. ${ }^{39}$

The interventions in the present study continued for 4 weeks; 2-month follow-up then showed a significant reduction at the end of the intervention. At 2-month followup, there was a significant increase in VAS score compared to that at the end of the intervention, but the decrease was still significant compared to the preintervention pain. This is supported by Akdeniz et al (2015), ${ }^{29}$ who concluded that VAS values before TENS and 3 months after TENS were not different from one another but were different at the follow-up. In addition, there was a contradiction with Costabile et al, ${ }^{8}$ who reported TENS effectiveness between 1 and 3 months. It seems that the lasting effect of TENS is questionable; the appropriate time for treatment reapplication and the issue of TENS tolerance also warrant further research.

Regarding QoL, there was a significant improvement in the TENS intervention group with 75 and $60 \%$ feeling delighted and pleased at the end of intervention and at 2-month follow-up, respectively, in comparison to $75 \%$ feeling unhappy and terrible before the TENS application. This significant improvement in QoL can be correlated with the achieved significant pain reduction. Therefore, the measurement of QoL provides a meaningful method to assess treatment impact in chronically ill subjects. ${ }^{40}$

The QoL results in the current study were in line with many studies that investigated the side effects of different types of pain, such as neuropathic pain, other chronic pain, arthritis, malignant pain, ${ }^{41-44}$ and somatic, psychogenic, and visceral origins of pain, on QoL. QoL scores in patients with pain were significantly lower than the scores of normal subjects. ${ }^{43}$ Decreased QoL is related to pain experienced on a daily basis and to increased pain intensity and frequency. Thus, patients who experience pain are more likely to experience problems in daily living activitites. ${ }^{45,46}$

This study had some limitations. First, a placebo TENS group was not included. Second, a small number of patients were studied. Third, data on the long-term effects of TENS were not available. Further studies may examine the appropriate treatment duration in terms of weeks and the time after which reapplication is required.

\section{Conclusion}

This study showed significant pain reduction in patients with ICO with improvement in their QoL. ICO is a chronic condition with weak response to pharmacological treatments; in addition, surgical options are irreversible and present with limited success. This highlights the importance of nonpharmacological treatment, such as TENS, which is a noninvasive, portable device that is easy to use and can be applied repeatedly.

\section{Disclosure}

The authors report no conflicts of interest in this work.

\section{References}

1. Davis BE, Noble MJ, Weigel JW, Foret JD, Mebust WK. Analysis and management of chronic testicular pain. J Urol. 1990;143(5):936-939.

2. Levine L. Chronic orchialgia: evaluation and discussion of treatment options. Ther Adv Urol. 2010;2(5-6):209-214.

3. Wesselmann U, Burnett AL, Heinberg LJ. The urogenital and rectal pain syndromes. Pain. 1997;73(3):269-294.

4. Granitsiotis P, Kirk D. Chronic testicular pain: an overview. Eur Urol. 2004;45(4):430-436.

5. Belanger GV, VerLee GT. Diagnosis and surgical management of male pelvic, inguinal, and testicular pain. Surg Clin North Am. 2016;96(3):593-613.

6. Kavoussi PK, Costabile RA. Orchialgia and the chronic pelvic pain syndrome. World J Urol. 2013;31(4):773-778.

7. Masarani M, Cox R. The aetiology, pathophysiology and management of chronic orchialgia. BJU Int. 2003;91:435-437.

8. Costabile RA, Hahn M, McLeod DG. Chronic orchialgia in the pain prone patients: the clinical perspective. J Urol. 1991;146:1571-1574.

9. Sasaki K, Smith CP, Chuang YC, Lee JY, Kim JC, Chancellor MB. Oral gabapentin (neurontin) treatment of refractory genitourinary tract pain. Tech Urol. 2001;7(1):47-49.

10. Levine LA, Matkov TG. Microsurgical denervation of the spermatic cord as primary surgical treatment of chronic orchialgia. J Urol. 2001;165(6 Pt 1):1927-1929.

11. Choaa RG, Swami KS. Testicular denervation: a new surgical procedure for intractable testicular pain. Br J Urol. 1992;70(4):417-419.

12. Sikiru L, Shmaila H, Muhammed S. Transcutaneous electrical nerve stimulation (TENS) in the symptomatic management of chronic prostatitis/chronic pelvic pain syndrome: a placebo-control randomized trial. Int Braz J Urol. 2008;34(6):708-714.

13. Elgohary H, Tantawy S, Eladl H. Impact of interferential current on pain relief among patients with orchalgia. Int J Physio Ther. 2016;3(4): $450-454$.

14. Clemens JQ, Nadler RB, Schaeffer AJ, Belani J, Albaugh J, Bushman W. Biofeedback, pelvic floor re-education, and bladder training for male chronic pelvic pain syndrome. Urology. 2000;56(6):951-955.

15. Cohen SP, Foster A. Pulsed radiofrequency as a treatment for groin pain and orchialgia. Urology. 2003;61(3):645.

16. Sluka KA. The neurobiology of pain and foundations for electrical stimulation. In: Robinson AJ, Snyder-Mackler L, editors. Clinical Electrophysiology. Philadelphia: Lippincott Williams \& Wilkins; 2008:107-149.

17. Ying KN, While A. Pain relief in osteoarthritis and rheumatoid arthritis: TENS. Br J Community Nurs. 2007;12(8):364-371.

18. Somers DL, Clemente FR. Transcutaneous electrical nerve stimulation for the management of neuropathic pain: the effects of frequency and electrode position on prevention of allodynia in a rat model of complex regional pain syndrome type II. Phys Ther. 2006;86(5):698-709. 
19. Warke K, Al-Smadi J, Baxter D, Walsh DM, Lowe-Strong AS. Efficacy of transcutaneous electrical nerve stimulation (TENS) for chronic lowback pain in a multiple sclerosis population: a randomized, placebocontrolled clinical trial. Clin J Pain. 2006;22(9):812-819.

20. Robb KA, Bennett MI, Johnson MI, Simpson KJ, Oxberry SG. Transcutaneous electric nerve stimulation (TENS) for cancer pain in adults. Cochrane Database Syst Rev. 2008;(3):CD006276.

21. Jensen MP, Chen C, Brugger AM. Interpretation of visual analog scale ratings and change scores: a reanalysis of two clinical trials of postoperative pain. J Pain. 2003;4(7):407-414.

22. Nickel JC, Siemens DR, Nickel KR, Downey J. The patient with chronic epididymitis: characterization of an enigmatic syndrome. J Urol. 2002;167(4):1701-1704.

23. Smith BH, Torrance N. Epidemiology of chronic pain. In: McQuay HJ, Kalso E, Moore RA, editors. Systematic Reviews in Pain Research: Methodology Refined. Seattle: IASP Press; 2008:233-246.

24. Breivik H, Collett B, Ventafridda V, Cohen R, Gallacher D. Survey of chronic pain in Europe: prevalence, impact on daily life and treatment. Eur J Pain. 2006;10(4):287-333.

25. Moore RA, Derry S, Taylor RS, Straube S, Phillips CJ. The costs and consequences of adequately managed chronic noncancer pain and chronic neuropathic pain. Pain Prac. 2014;14(1):79-94.

26. Vance CG, Dailey DL, Rakel BA, Sluka KA. Using TENS for pain control: the state of the evidence. Pain Manag. 2014;4:197-209.

27. Johnson M. Transcutaneous electrical nerve stimulation: mechanisms, clinical applications and evidence. Br J Pain. 2007;1:7-11.

28. Gildenberg PL. History of electrical neuromodulation for chronic pain. Pain Med. 2006;7:7-13.

29. Akdeniz E, Bolat M, Akdeniz S. Treatment of idiopathic chronic orchialgia with transcutaneous electrical nerve stimulation (TENS): a preliminary result. Int J Surg Med. 2015;2(1):8-11.

30. Sharma N, Rekha K, Srinivasan JK. Efficacy of transcutaneous electrical nerve stimulation in the treatment of chronic pelvic pain. $J$ Midlife Health. 2017;8(1):36-39.

31. Johnson MI. Transcutaneous electrical nerve stimulation (TENS). In: Kitchen S, editor. Electrotherapy: Evidence-Based Practice. Edinburgh: Churchill Livingstone; 2002:259-286.

32. Sluka KA, Walsh D. Transcutaneous electrical nerve stimulation: basic science mechanisms and clinical effectiveness. J Pain. 2003;4(3):109-121.

33. Sluka KA, Bjordal JM, Marchand S, Rakel BA. What makes transcutaneous electrical nerve stimulation work? Making sense of the mixed results in the clinical literature. Phys Ther. 2013;93(10):1397-1402.
34. de Tommaso M, Fiore P, Camporeale A, et al. High and low frequency transcutaneous electrical nerve stimulation inhibits nociceptive responses induced by $\mathrm{CO}_{2}$ laser stimulation in humans. Neurosci Lett. 2003;342(1-2):17-20.

35. Chakour MC, Gibson SJ, Neufeld M, Khalil Z, Helme RD. Development of an active placebo for studies of TENS treatment. In: Devor M, Rowbotham MC, Wiesenfeld-Hallin Z, editors. Progress in Pain Research and Management. Proceedings of the IXth World Congress on Pain. Seattle: IASP Press; 2000:987-992.

36. Walsh DM, Liggett C, Baxter D, Allen JM. A double-blind investigation of the hypoalgesic effects of transcutaneous electrical nerve stimulation upon experimentally induced ischaemic pain. Pain. 1995;61(1): 39-45.

37. Dailey DL, Rakel BA, Vance CG, et al. Transcutaneous electrical nerve stimulation reduces pain, fatigue and hyperalgesia while restoring central inhibition in primary fibromyalgia. Pain. 2013;154(11):2554-2562.

38. Johnson MI, Tabasam G. A double blind placebo controlled investigation into the analgesic effects of interferential current (IFC) and transcutaneous electrical nerve stimulation (TENS) on cold induced pain in healthy subjects. Physiother Theory Pract. 1999;15:217-233.

39. Vance CG, Rakel BA, Dailey DL, Sluka KA. Skin impedance is not a factor in transcutaneous electrical nerve stimulation effectiveness. $J$ Pain Res. 2015;8:571-580.

40. Aljumaily A, Al-Khazraji H, Gordon A, Lau S, Jarvi KA. Characteristics and etiologies of chronic scrotal pain: a common but poorly understood condition. Pain Res Manag. 2017;2017:5. Article ID 3829168.

41. Wang XS, Cleeland CS, Mendoza TR, et al. The effects of pain severity on health-related quality of life: a study of Chinese cancer patients. Cancer. 1999;86(9):1848-1855.

42. Haythornthwaite JA, Benrud-Larson LM. Psychological aspects of neuropathic pain. Clin J Pain. 2000;16(2 Suppl):S101-S105.

43. Becker N, Bondegaard Thomsen A, Olsen AK, Sjøgren P, Bech P, Eriksen J. Pain epidemiology and health related quality of life in chronic non-malignant pain patients referred to a Danish multidisciplinary pain center. Pain. 1997;73(3):393-400.

44. Hill CL, Parsons J, Taylor A, Leach G. Health related quality of life in a population sample with arthritis. J Rheumatol. 1999;26(9):2029-2035.

45. Won A, Lapane K, Gambassi G, et al. Correlates and management of nonmalignant pain in the nursing home. J Am Geriatr Soc. 1999;47:936-942.

46. Hunfeld JA, Perquin CW, Duivenvoorden HJ, et al. Chronic pain and its impact on quality of life in adolescents and their families. J Pediatr Psychol. 2001;26(3):145-153.
Journal of Pain Research

\section{Publish your work in this journal}

The Journal of Pain Research is an international, peer reviewed, open access, online journal that welcomes laboratory and clinical findings in the fields of pain research and the prevention and management of pain. Original research, reviews, symposium reports, hypothesis formation and commentaries are all considered for publication.

\section{Dovepress}

The manuscript management system is completely online and includes a very quick and fair peer-review system, which is all easy to use. Visit http://www.dovepress.com/testimonials.php to read real quotes from published authors. 